\title{
Manpower: Compendium of deliberate mistakes
}

\author{
JAMES PARKHOUSE
}

A chapter of accidents would be unfortunate; a compendium of deliberate mistakes seems like a truer but less excusable epitome of our efforts to deal with the problems of postgraduate training and medical staffing. Can we after all do no better than this? We should look at our credibility rating with patients and other health professionals, including the managers and administrators whom it is fashionable to suspect or deride.

The more senior of us should also be aware of what many of our younger professional colleagues think, often with great bitterness, about the attitudes and the style of hospital medicine. The last thing that I wish is for my research into doctors' careers to be pulled into a medicopolitical arena. But voices of those to whom the exigencies of the system deny free, open speech deserve to be heard. This may sound an extreme comment: "The hospital service is full of petty bureaucrats, inconsiderate, and often vicious people. I feel that the majority of these medical and nursing staff are more concerned with their own egos than patient care." I have read too many like it from my respondents to feel complacent or comfortable.

Since about the time of Mrs Renée Short's select committee report several factors have been operating, or threatening to operate, at the bottom end-the sharp end-of hospital medical staffing. ${ }^{1}$ Firstly, there was the senior house officer freeze. The logic behind this was clear enough: to prevent any further expansion in the pool of senior house officers, while at the same time tightly restricting sideways escape routes into the clinical assistant, hospital practitioner, and associate specialist grades. Instead of the metaphorical toothpaste tube being just squeezed in the middle, by attacking the registrar grade, it would be squeezed at the bottom and in the middle simultaneously so that the bulge must come to the top in the form of consultant expansion.

I found this logic unconvincing because it seemed to me that in the absence of positive changes higher up the ladder the senior house officer freeze would simply make it necessary for people to find alternative ways of evading the consequences. The seams of the tube, in fact, split under the strain of having to meet clinical commitments while arranging for the same number of juniors to work lighter duties. The result is a mess; a half concealed splurge of permanent locum registrars and clinical assistants with not only nine but 12,13 , or 14 sessions to eke out the rotas.

\section{Difficult to plug service gaps}

Secondly, there have been the General Medical Council regulations introducing limited registration for a maximum of five years. I admired the firmness with which these proposals were advocated, and was frankly surprised that they carried enough support at the time to become implemented. But once again, although there is much to be said for the arrangements in principle, their practical effect in the absence of changes elsewhere in the system has been mainly negative. Bluntly, it has become more difficult for employers to plug service gaps by putting doctors whom nobody else shows much sign of wanting into jobs with dubious or non-existent

Medical Careers Research Group, The Churchill Hospital, Headington, Oxford OX3 7LJ

JAMES PARKHOUSE, MD, FFARCS, director educational approval. When we can no longer even paper over the cracks we thus expose the shabbiness of our ways.

Thirdly, there have been the Department of Health and Social Security and Home Office regulations on work permits and the restriction of postgraduate training for immigrant doctors to four years. Though there was a great deal of pressure from within the medical profession for this legislation, it always seemed to me the wrong way of tackling the problem. If the career structure and hence the medical staffing structure of the NHS were put right, and as a consequence good postgraduate training became a matter of course for everyone, the difficulties faced by overseas doctors and our excessive dependence on their services would fade away without any need for legislation. Conversely, no legislation will solve the problem by itself; it simply creates new ones, as we now begin to see. Some of the same things could be said about the sponsorship scheme for overseas doctors. Although this is a positive attempt at improvement, it is, inevitably, seen by some people as a means of importing overseas doctors in order to maintain the status quo. And it shares with the DHSS regulations a potentially disastrous evasiveness about what postgraduate training should consist of and how its provision is to be monitored.

Fourthly, there is relentless pressure, which has so far been resisted, for a reduction in the number of medical school places.

\section{Cushion of uncommitted doctors}

All these developments are taking something away from the bottom of the medical staffing structure. In particular, they are diminishing what Sir George Smart and I described as the "cushion" of relatively uncommitted doctors, mostly from overseas, who have been willing to take up junior posts mainly needed for service purposes and often in the remoter corners of the health service. This removal at the bottom is being done without putting any alternative at the top, or in the middle, with predictable results.

The problems of finding junior orthopaedic staff in Stafford were obvious to me when I visited the district last year and, as John Woodyard says, they are apparent in other districts. ${ }^{2}$ His views reached the Guardian, ${ }^{3}$ but the letters that were published in response sadly illustrate how far we still are from any agreement about solutions. ${ }^{45}$ Bodies such as the royal colleges and the craft committees of the BMA, by definition, represent their members. Their strength is proportional only to their ability to speak on behalf of these members. Yet although presidents, chairmen, and other designated spokesmen have repeatedly professed support on behalf of the organisations that they represent-for example, for a revised career structure with consultant expansion-it often seems when talking to consultants at district level that the perceived need is for more juniors, with little enthusiasm for the kind of changes that are talked about centrally.

Different specialties have different problems. The briefest glance at the existing ratios of junior staff to consultants in accident and emergency is enough to illustrate the nature and magnitude of the difficulties to be faced there. Meanwhile, many health authorities, with new management structures, are beginning to think seriously about legitimising the alternatives to a consultant expansion that seems likely to be costly and endlessly contentious. One way is through the employment of more associate specialists and clinical assistants who will get on with the job without requiring a 
meshwork of extra junior doctors between themselves and the patient.

Some of the emphasis has now shifted to the senior registrar grade with the setting up of the Joint Planning Advisory Committee. There is a danger that this initiative will, like the Platt report, divert attention from the fundamental problems that have always been at the senior house officer and registrar stage. The real priority at senior registrar level is to recognise that consultant expansion, if it is to occur on a substantial scale, needs more senior registrars to fuel it-not for ever, but while the expansion is in progress.

If this is the way we intend to go most of our problems could be solved by converting a substantial number of registrar posts into senior registrar posts. But this would really force the issue. Districts would need to find the money for consultant expansion; consultants would need to accept its implications, with existing or somewhat reduced levels of junior staffing; and the fear of producing time expired or unemployed senior registrars would be a dread deterrent.

\section{Need for short term strategies}

We have prevaricated so long over postgraduate training and hospital medical staffing that time really has run out. What we need to do now is think of some short term strategies that will keep a show on the road while holding open the long term options. We should be talking with managers about accountability as the price of our independent professional judgment. Clinical freedom without corporate responsibility may happily be dead; long live clinical leadership, both in policy discussion and in its implementation.

James Johnson is right that we should think the unthinkable and seriously discuss a subconsultant grade. ${ }^{6}$ We cannot too lightly discard the idea of more than one consultant or specialist grade as being impracticable. Up and down movement within the top bracket might be a sensible variant on the time limited contract that Alan Maynard and others have seriously proposed.' Also, we should recognise that a system as complex and elastic as the NHS needs a few cushions-well fashioned and not just hiding shoddiness under cheap embroidery. Altogether, there is a lot more talking to do and it has to be done quickly. To restore the morale of the service and get away from the awful disenchantment with hospital careers that so many young doctors have we need something better than a panic response to a self induced crisis.

1 Social Services Committee. Fourth report from the social services committee 1980-81: medical education with special reference to the number of doctors and the career structure in hospitals. London HMSO, 1981. (HC 31-I)

2 Woodyard JE. Orthopaedic iunior staff. Br Med f 1986;292:902.

3 Woodyard J. The doctors' malaise that threatens our good health. Guardian 1986 March 24:13 (col 2).

4 Perry FS. Cold comfort in the NHS. Guardian 1986 March 31:10 (col 2)

5 Higham JH. Cold comfort in the NHS. Guardian 1986 March 31:10 (col 2)

6 Johnson JN. Cycle of gloom over manpower. Br Med F 1985;291:361-2.

Maynard A. The nonsense of doctors' contracts. Health and Social Services fournal 1985 Dec 19-26:1610.

(Accepted 8 April 1986)

\title{
Bed numbers and good medical education
}

\author{
IAIN E GILLESPIE, DONALD LONGSON
}

One of the decisions being implemented throughout the National Health Service is to reduce the number of acute general surgical and medical beds. The various regional health authorities argue that such reductions will be compatible with meeting their service commitments but have taken less notice of the implications of such changes for teaching.

In teaching hospitals the cutback in these beds is exacerbated by the expansion of highly specialised regional services that encroach on the dwindling pool of beds available to general services and emergencies. Most of these expanding specialties operate in relative clinical isolation or collaborate with other departments for clearly specified needs. There are many reasons why they make a limited, though useful contribution to undergraduate medical education, especially in its early phase. It is against this background that clinical teaching must survive and yet it receives little attention in the current medicopolitical maelstrom. It is tacitly assumed that education is infinitely adaptable and that its requirements can be met by conscience money, square metres of teaching space, and the funding by the NHS of posts in the university-even if these posts are in subjects of small curricular importance. This is a lamentable underestimation of the needs of clinical medical education.

The dispersal of students to district general hospitals is an excellent educational innovation. Students return from these clerkships with enhanced confidence and maturity; they have had

\section{University of Manchester, Manchester M13 9PT}

IAIN E GILLESPIE, MD, FRCS, dean of the medical school

DONALD LONGSON, MB, FRCP, chairman, board of the faculty of medicine

Correspondence to: Professor Gillespie, University of Manchester, Stopford Building, Oxford Road, Manchester M13 9PT. closer contact with patients than is possible in the teaching hospital; in many instances they have had excellent teaching. But, in general, they have been falsely credited with competence in basic clinical methods and their performance has not been systematically checked and corrected. Our enthusiasm for this type of experience is unfeigned and we would not wish to revert to the old system. It does not follow, however, that we view external clerkships as a possible substitute for training in the teaching hospital; they are complementary to it. There is an undiminished need for early education to take place in an educational establishment with its discipline and curricular overview. For instance, the success of the external clerkships depends greatly on the training in basic clinical method inculcated in the early part of the clinical course, and the teaching of clinical method is the first casualty when the inpatient services are curtailed; perhaps our policy makers ought to be better informed about the matter.

\section{Fear of clinical uselessness}

"Clinical method" includes all the tools that the doctor employs when confronting a patient. It includes the verbal skills necessary to explore the patient's subjective experiences and his circumstances in life, the sensory skills for the doctor to observe malfunctions and distortions of anatomy, and the verbal skills of explanation and advice. Without "clinical method" even the polymath is reduced to clinical uselessness. These skills increase in effectiveness and range throughout professional life but a minimum package is necessary before the student can start to role play and benefit from exposure to specialties where there are already complaints of deficient clinical skills. The clinical tyro must surmount great obstacles: many social, psychological, and even sexual inhibitions must be overcome; a higher degree of articulateness is required than many young people possess and it is against this delicate background that, often for the 